\title{
Horizontes de significado y metamorfosis óntica: Sobre el destino de un diálogo roto*
}

\author{
Juan Blanco Ilari' \\ Comisión Nacional de Investigaciones Científicas y Técnicas (CONICET) \\ Universidad Nacional de General Sarmiento (Argentina) \\ Universidad Católica Argentina (Argentina) \\ Universidad de Belgrano (Serbia)
}

Recibido: octubre 4 de 2015 - Revisado: noviembre 3 de 2015 - Aceptado: noviembre 20 de 2015

Referencia formato APA: Blanco-Ilari, J. (2015). Horizontes de significado y metamorfosis óntica: Sobre el destino de un diálogo roto. Revista

Cientifica Guillermo de Ockham, 13(2), 25-34.

\section{Resumen}

En este trabajo analizó la brecha que separa el discurso filosófico del discurso cotidiano. La tesis general sostiene que el horizonte de sentido en el que estamos insertos nos compromete con una ontología que, en ocasiones, contradice la ontología develada por la mirada objetiva. Para la contrastación de esta hipótesis, he seguido un método crítico de análisis semántico y pragmático de algunas categorías centrales en el debate. Esa metodología me llevó a poner en relación universos del discurso heterogéneos. Tomo algunos ejemplos en los que esa heterogeneidad se hace evidente e irreconciliable: Heidegger y su noción de "significado", "facticidad" y "mundo"; Taylor y la aporía del cambio de objeto, entre otros. Me interesa subrayar la imposibilidad de hallar un terreno en común en el que estos "mundos" puedan encontrarse. El tono general del trabajo es el de un alegato en favor de la pluralidad discursiva, de la irreductibilidad del saber común, doxástico, a un saber adecuado al discurso científico, epistémico.

Palabras clave: Horizontes, significado, ontología, diálogo, inconmensurabilidad

\section{Horizonts of meaning and ontic metamorphosis: On the fate of a broken dialogue}

\section{Abstract}

In this paper the gap between philosophical discourse and common language was analyzed. The general thesis sustains that the horizon of meaning in which we operate commits us with an ontology that sometimes contradicts ontology unveiled by the objective view. For the contrasting of this hypothesis I followed a critical semantic and pragmatic method of some main categories in the debate. This methodology drove me to put in relationship heterogeneous

* El presente artículo se enmarca dentro del proyecto de investigación Comprensión y pertenencia: la superación hermenéutica del objetivismo, aprobado y financiado por la Comisión Nacional de Investigaciones Científicas y Técnicas (Conicet) y por la Universidad Nacional de General Sarmiento (UNGS). El proyecto es trianual (2013-2016). En este trabajo desarrollo algunas de las líneas directrices de dicha investigación.

1. El autor es doctor en Filosofía por la Universidad Nacional de La Plata (donde también se recibió de profesor y licenciado). En la actualidad se desempeńa como Investigador de la Comisión Nacional de Investigaciones Científicas y Técnicas y como docente en la Universidad Nacional de General Sarmiento, en la Universidad Católica Argentina, y en la Universidad de Belgrano. Codirige el proyecto Lenguaje y lazo social: sujeción y crítica en algunas corrientes del pensamiento contemporáneo (PIP-Conicet) y participa como miembro investigador en el proyecto Experiencia y experimentación en la modernidad tardía, subvencionado por la Universidad de Buenos Aires y dirigido por el doctor Naishtat. E-mail: juan_blanco2001ar@hotmail.com 
universes of discourse. I take some examples in which that distance is evident and irreconcilable: Heidegger and his notion of "meaning," "facticity" and "world." Taylor and the change subject aporia, among others. I want to emphasize the impossibility of finding a common ground in which these "worlds" can find each other. The general tone of the work is a plea for the discursive plurality, of the irreducibility of common knowledge, doxastic, to scientific epistemic discourse.

Keywords: Horizonts, meaning, ontology, dialogue, incommensurability

\section{Horizonte de significado e metamorfose ôntica: Sobre o destino de um diálogo quebrado}

\section{Resumo}

Neste trabalho, analisou-se a lacuna que separa o discurso filosófico do discurso cotidiano. A tese geral sustenta que o horizonte de sentido no qual estamos inseridos nos compromete com uma ontologia que às vezes contradiz a ontologia revelada pelo olhar objetivo. Para contrastar essa hipótese, segui um método crítico de análise semântica e pragmática de algumas categorias centrais deste debate. Essa metodologia me levou a colocar em relaçáo universos do discurso heterogêneos. Tomo alguns ejemplos a partir dos quais essa heterogeneidade se torna evidente e irreconhecível: Heidegger e sua noção de "significado", "facticidade" e "mundo"; Taylor e a aporia da mudança do objeto, entre outros. Interessa-me sublinhar a impossibilidade de achar um terreno em comum, no qual estes "mundos" possam encontrar-se. O tom geral do trabalho é o de um apelo a favor da pluralidade discursiva, da irredutibilidade do saber comum doxástico, de um saber adequado ao discurso científico, epistêmico.

Palavras-chave: Horizontes, significado, ontología, diálogo, inconmensurabilidade

\section{Introducción}

Buena parte de la tradición filosófica se ha desarrollado al calor de una imagen matricial. Esa imagen representa una iluminación de la tarea del pensar (de cierto tipo de pensar), y al mismo tiempo le marca su norma. Se nos invita, a través de ella, a emigrar de la cotidianidad media, del mundo de la praxis habitual, para elevarnos al reino de la episteme. Un gesto de retirada, una alienación sin descanso (permanente, siempre renovado), define el campo del conocimiento. Desde el instante en que el esclavo se libera de los pesados grilletes de la doxa, del sentido común, de la experiencia inmediata, comienza su asenso liberador hacia el mediodía.

Pero, ¿̨ómo han quedado los que siguen habitando en las profundidades de la caverna? Ellos siguen hablando su lengua materna, siguen adheridos a sus prácticas, ritos, símbolos, etc. Continúan con sus temores, sufrimientos, esperanzas. Hablan de la verdad, de la belleza, del bien y la justicia sin apelar a definiciones absolutas, eternas y necesarias. No necesitaron ningún Sócrates para fundar la comunidad.
Hace tiempo que trato de recrear el momento en que el liberto se reencuentra con sus antiguos amigos, con quienes fueron sus iguales. Intento dimensionar el choque idiomático, la conmoción de perspectivas, la inconmensurabilidad de sus miradas. Una cosa es clara: el encuentro se produce "allí abajo", en la oscuridad de la caverna. Una vez reinstalado en su antigua morada, el filósofo debe hacer un duelo. El que porta el saber superior (episteme) debe asimilar la imposibilidad de volver a dialogar con los que ha dejado abajo. Este trabajo recorre algo de esa imposibilidad.

El final de la alegoría es algo difuso. Los que moran en la doxa, no solo no comprenden, sino que se sienten amenazados por quien se ha transformado en intruso y le dan muerte. Son muy pocos los pensadores que han intentado comprender a los atenienses que llevaron adelante el juicio a Sócrates. Sin embargo, todavía tiene sentido preguntar: ¿qué está detrás de la acusación de Anyto, Méleto y Licón? ¿Es una mera coincidencia que el acusador más activo en el juicio contra "la filosofía" sea, precisamente, un "poeta"?2

2. Uno podría leer la historia del pensamiento occidental como una extensión de aquel famoso juicio. La filosofía no ha podido todavía justificar su pretensión independentista ante la poesía (que en la época de Sócrates comprendía el arte, la historia y la retórica). 
El trabajo que sigue está animado por estas inquietudes. Veo en el discurso del filósofo (aquel que se autocomprende heredero de la imagen platónica) ${ }^{3}$ un desajuste, una desavenencia en relación con otros tipos de discursos, en particular el hablar común, cotidiano, doxástico. Convencido de que el filósofo y el hombre común habitan mundos diferentes, trataré de mostrar cuál es el modus operandi de la episteme; qué tipo de lejanía genera. Procederé en dos movimientos. En primer lugar, sobrevolaré el maltrato que el discurso del saber riguroso (fundamentado, verdaderamente racional, y por tanto liberador) le propina al campo de la experiencia cotidiana, naturalmente compartida. La anábasis del conocimiento no se hace sin un desprestigio de la experiencia. Los otros discursos en los que decimos nuestro modo de estar en el mundo (religioso, estético, histórico, etc.) quedan relegados al ámbito de la sombras.

En el segundo punto del trabajo me centro en la noción de "intraducibilidad" que separa el hablar propio del sujeto encarnado, del hablar epistémico, objetivo, neutral. Tomo algunos ejemplos que muestran la inconmensurabilidad idiomática (y por tanto ontológica) que aleja ambos tipos de discursos y rompe la posibilidad del diálogo. Allí retomo la aporía del cambio de objeto para mostrar lo que sucede cuando queremos forzar una traducción.

La conclusión quisiera ser un alegato en favor de la experiencia significativa tal como se nos da en su generosidad primaria, una apuesta por la riqueza y plurivocidad del hablar cotidiano. Este desagravio cuenta, también, con una amplia y reconocida tradición dentro del pensamiento filosófico. La cita del epígrafe es solo un ejemplo. Sin embargo, la tentación teoricista (como la llama Heidegger) acecha permanentemente, quizá porque representa una promesa de conocimiento sobrehumano y junto a él, la adquisición de un poder casi divino.

\section{La depreciación de la doxa}

En el vivir cotidiano estamos entregados a las cosas de las que nos preocupamos. Nos sumergimos en nuestra experiencia atareados por nuestro entorno, a punto de quedarnos detrás del mundo. Es un hecho fenomenológico un tanto elemental, que el primer dato que encontramos es el mundo (lo otro), no el yo. Una buena porción del pensamiento filosófico llama actitud natural a este vivir inmerso en el mundo. La espontaneidad con la que transitamos dicha actitud natural, la inocencia con la que nos dejamos embargar por las cosas, sucesos o personas, puede verse trastocada y seriamente lesionada por el advenimiento de una actitud que me distancia de todo ello y lo pone "bajo cuestión". La actitud contemplativa, el giro "reflexivo", puede ser un acontecimiento (algo imprevisto y rupturista) o ser algo artificialmente provocado. Ambos casos presuponen la distensión de un vínculo de pertenencia que me mantenía unido al mundo de una manera irreflexiva. A este tipo de "estar en el mundo" le corresponde el campo de la doxa (según el clásico dualismo que recorre buena parte del pensamiento occidental).

En la contemplación, entonces, nos "des-vivimos"; rompemos la familiaridad del vivir habitual. Para pensar en términos filosóficos sobre lo que hacemos cuando hacemos lo que hacemos, hay que poner entre paréntesis las certezas y dudas propias del mundo compartido con otros. Ese movimiento de alejamiento lleva una promesa cuya fuerza vinculante es innegable: la promesa de la verdad. Entonces, para descubrir si algo es auténticamente, el filósofo debe abandonar el mundo de las apariencias donde se siente natural y originariamente en casa, como hizo Parménides cuando fue transportado hacia arriba, más allá de las puertas de la noche y el día, hasta el camino divino que se extendía, "bien alejado por cierto de la ruta trillada por los hombres" (Arendt, 2002, p. 47).

Lo que ha quedado fijado como imperativo es que para conocer hay que emigrar. Al "afuera", instaurado por el pensar, llegamos desvinculándonos de las cosas tal como se nos ofrecen a la mirada y comercio diario.

El sujeto que emigra es un sujeto desvinculado. $\mathrm{Su}$ función es hacer de todas las cosas objetos de conocimiento; es decir, establecer como patrón relacional la "observación descomprometida". El imperativo epistémico de abandonar el sujeto encarnado, inserto en el reino de la doxa, para consagrar al sujeto epistémico (universal y necesario), nace junto con la filosofía y se radicaliza durante la modernidad. ${ }^{4}$

3. Soy consciente de la hipersimplificación que anida en la expresión "la filosofía". Sé que por filosofía entendemos algo demasiado abarcador, plural, heterogéneo. Cuando hablo de "la filosofía", me estaré refiriendo a la que se compromete con la surgida de Platón y su metafísica, la que tiene en la alegoría de la caverna su relato fundacional. Es claro que pensadores como Heidegger, Wittgenstein, Rorty, etc. no entrarían en ese conjunto, y sin embargo también son bien llamados "filósofos". Esto me pone de cara con el problema de la naturaleza de la filosofía, pero este no es el lugar, ni yo me siento indicado para intentar semejante empresa.

4. Taylor consigna la revolución cartesiana como la consagración del ideal del sujeto desvinculado. Esta noción se manifiesta "en el dualismo clásico, donde el sujeto se aleja incluso de su cuerpo, al que es capaz de observar como un objeto, pero pervive más allá del dualismo en la exigencia contemporánea de una ciencia neutral y objetivadora de la vida y la acción humana” (Taylor, 1997, p. 27). 
Si nuestra tierra natal es el mundo tal como se nos ofrece en la experiencia cotidiana, entonces todo un esfuerzo de desubjetivación es requerido para abandonar nuestra morada y habitar en el extranjero. Una vez instalado el principio de exterioridad, era solo cuestión de tiempo para que se produzca la escisión dentro del mismo sujeto: "sujeto de la experiencia era el sentido común, presente en cada individuo [...] mientras que sujeto de la ciencia es el nous o intelecto agente, que está separado de la experiencia, impasible y divino (Agamben, 2007, p. 15). ${ }^{5}$

Sin embargo, algunos pensadores no se dejaron arrastrar tan fácilmente por el canto de sirenas que representaba la vocación por la episteme. Observaron que al dirigirse al "lugar del verdadero conocimiento", no obtenían una mejor mirada de lo que vivían mientras habitaban las sombras de la caverna. Por el contrario, lo que advertían en la región del saber eran otras cosas, literalmente otro mundo. En otras palabras, adoptar la actitud teóricocontemplativa implica eliminar el objeto de experiencia. La disolución suele estar seguida de la sustitución del ese objeto por otro.

Muchos siglos después de Platón, Husserl señala la necesidad de poner entre paréntesis la fe en el mundo, abrir una epoché en la que situar la experiencia tal como se nos da, para inaugurar el quehacer filosófico. Como bien recuerda Presas, "hay algo de violencia y de ruptura tanto en la imagen de Platón como en las palabras mismas con que Husserl alude al gesto inicial del filósofo: Aufbruch, Einbruch, Durchbruch, provenientes todas de brechen, la acción de quebrar, romper, destruir" (Presas, 2009, p. 18).

Esta "violencia" ejercida por la filosofía fue advertida desde su mismo natalicio. La "retórica" -disciplina más antigua que la filosofía- veía en la pretensión omniabarcante del nuevo modo de pensar apodíctico y absoluto una tendencia a nihilizar los estratos de saber que conformaban el basamento de la comunidad política. El debilitamiento era causado por la incorporación, en las argumentaciones prácticas, de un baremo ajeno a dicho campo argumentativo. La episteme, al comprobar que el campo de la opinión no se ajusta a su criterio de "justificación", decreta que es un conocimiento "injustificado" y por lo tanto un no conocimiento.

Pero los endoxai (las opiniones comunes) eran fuente de identidad y pertenencia y mantenían reunida la co- munidad de hablantes. La exigencia de "abandonar" ese plexo de sentido era equivalente a transformarse en un bárbaro. En la obra de Platón este desajuste doxa-episteme adquiere tonos dramáticos. En el Libro I de la República (por tomar solo un ejemplo), Trasímaco quiere hacerle entender a Sócrates que el hecho de no poder satisfacer el requisito por él pretendido (definir en términos absolutos el concepto de justicia), no implica un no saber acerca de la justicia. El problema no radica en no poder cumplir con lo requerido, sino en querer someter las prácticas judiciales a criterios de satisfacción ajenos a este dominio. El problema no estriba en la respuesta, sino en el tono (y la pretensión) de la pregunta.

La configuración del nuevo saber está atravesada por una despedida. Como afirma la cita de Arendt, conocer es abandonar aquellas certezas básicas que conforman nuestra existencia cotidiana. Este abandono marca una lejanía, cada vez más pronunciada, entre el lenguaje que hablan los que todavía habitan la doxa, y el que utilizan los que se han encaramado a la altura de la episteme. Cuando el liberto retorna a la oscuridad de la caverna se observa una fuerte disonancia discursiva. Los que moran "abajo" advierten una suerte de vejación sobre sus modos habituales de hablar.

La extrańeza de la "verdad" queda cristalizada en la creación discursiva de ideolectos cada vez más excluyentes. La "realidad", que se oculta tras las apariencias, se expresa en un lenguaje especial, hipertecnificado, cuyo código solo puede ser manejado por aquellos que se han atrevido a deshacerse del lenguaje natural.

El nuevo modo de pensamiento era asequible exclusivamente a un grupo muy reducido de iniciados y requería un esforzado adiestramiento para ser comprendido. Mientras su campo fue la matemática o la medicina, el nuevo universo de conocimiento no representó molestia alguna, pero cuando se extralimitó al querer ingresar en los asuntos humanos (política, ética, historia), necesitó un límite. La filosofía tuvo, desde su inicio, un adversario a quien combatía y en relación con cual se autodefinía. No hay verdadera comprensión de Platón sin un correcto acercamiento a Isócrates. El debate filosofía-retórica es el debate teoría-praxis, distanciamiento-participación, pensamiento de especialistas-pensamiento del sensus communis.

5. La superación de la contingencia, adherida a la experiencia cotidiana, está detrás de la coronación de la episteme durante la modernidad. "Para Bacon y Descartes [...] el universo tolemaico había perdido definitivamente toda vigencia, y la experiencia geocéntrica basada en el sentido común que le había conferido plausibilidad fue desechada a favor de una comprensión más verdadera del cosmos, una comprensión que procuraba superar la perspectiva finita del sujeto humano contingente" (Jay, 2009, p. 44). 
Vemos así surgir un problema que puede adquirir ribetes algo dramáticos: de ida: cómo traducir el lenguaje de los que "saben" (lenguajes especiales) al lenguaje de los que "viven en las sombras". Pero también de vuelta: cómo asegurar que la terminología inventada por los que ostentan el saber se refiere también a lo que nos referimos los que nos mantenemos dentro los márgenes de la doxa.

La retórica antigua tenía clara conciencia de que ciertas cosas solo pueden verse desde cierto lugar. Existía una relación de codeterminabilidad entre "pertenencia" y "mundo". En el ámbito de los asuntos humanos es menester ser parte de la polis y estar nutrido y conformado por sus usos y costumbres para poder tomar parte en las discusiones. Solo quienes habitan la polis pueden advertir lo desquiciado de las argumentaciones filosóficas. ${ }^{6}$

Sin este requisito de presociabilidad el diálogo es imposible, porque las creencias básicas que lo sustentan no están presentes. No se trata de un mero postulado, sino de un dato fenomenológico elemental; sin un elemento vinculante no puede haber diálogo posible.

Como su ámbito de operaciones era la praxis, la retórica tenía una fuerte tendencia a no dejarse engañar por los razonamientos descontextualizados. Por ello, la noción de "auditorio", conjuntamente con la de "lugar común", preformaban el ámbito de lo argumentable y el tipo de argumentación pertinente. No tener en cuenta estos dos elementos básicos en la argumentación es propio de un insensato. ${ }^{7}$ Precisamente así llama Aristóteles a quien pretende entender un orden de realidad en términos de otro. ${ }^{8}$

La idea de auditorio es elástica. Puede extenderse (auditorio universal) y contraerse (auditorios específicos; por ejemplo, los filósofos del siglo XX, o más aún, los filósofos hegelianos del siglo XX); y marca, según los clásicos de la retórica, el perímetro dentro del cual se jugará el discurso en cada ocasión. ${ }^{9}$ El auditorio puede ser entendido en términos de una comunidad de hablantes, un conjunto de personas que hablan el mismo lenguaje porque remiten a la misma experiencia. El auditorio es una koinonia, y está definida por un conjunto de creencias, rituales, representaciones, símbolos, etc. que constituyen algunos de los "lugares comunes" al que el miembro puede acudir en sus argumentaciones.

\section{Marcos referenciales y órdenes discursivos}

La preocupación de los maestros de retórica era mantener a resguardo la experiencia vital común (esencialmente política) de la desaparición en manos de la actitud objetivante del saber filosófico.

Pronto, esta necesidad de custodiar la experiencia fenoménica, mundanal, se incorporó al pensar filosófico mismo y generó una fractura en su interior. La filosofía tiene, ahora, la potestad de denunciar a la filosofía (paradójicamente en nombre de la "verdadera filosofía").

Quizá uno de los que mejor representa esta línea de pensamiento en nuestra época sea Heidegger. En su curso de posguerra (1919), ${ }^{10}$ se encuentran en forma condensada los grandes temas que lo preocuparán hasta la década de 1930. La intención de ese curso es doble: por un lado, rescatar los conceptos de "significatividad" (Bedeutsamkeit), "facticidad" (Faktizität) y "mundo" (Welt) del olvido provocado por la filosofía moderna; y por otro, mostrar las dańosas consecuencias que la filosofía dominante tiene para nuestra experiencia cotidiana, inmediata.

En este tramo de su pensamiento, Heidegger insiste en que el modo como los entes hacen su aparición es subsidiario del tipo de relación que establezcamos con ellos. Es decir, al variar nuestra actitud hacia los entes

6. En El giro hermenéutico, Gadamer recorre algunos de los elementos que se presuponen para poder adquirir el saber práctico. Se debe, dice retomando una antigua tradición, partir del "que" (hoti), del "legómena", los "doxai" generales sobre lo bueno, el "eudaimonismo", los "aretai", etc. "Aristóteles advirtió en lo práctico repetidamente de la aparente agudeza de argumentos que no hacen honor a los hoti. Lo único que importa es el oikeios logos. Solo quien ocupa un lugar en la sociedad es capaz de darse cuenta de lo insostenible de argumentaciones extrańas al objeto [...] Aristóteles va tan lejos como para dar esto también como válido para la "política". Quien como ciudadano de una ciudad no haya desarrollado un buen sentido político, ese no puede aplicar razonablemente el saber de lo general". (Gadamer, 1998, p. 190/1)

7. Arendt sugiere que el error de Sócrates fue hablar ante la asamblea, que lo estaba juzgando como si estuviera frente a sus amigos filósofos. Es decir, utilizó la "dialéctica" (dialegesthai) en lugar de la persuasión (rhétorikê). "Sócrates insistió en discutir el asunto con sus jueces del mismo modo en que acostumbraba a hablar sobre todo género de cosas con este o aquel ciudadano ateniense o con sus propios discípulos, y creyó que así podría llegar a algún tipo de verdad y persuadir a los demás de ella. Sin embargo, la persuasión no proviene de la verdad, sino de las opiniones y solo la persuasión tiene en cuenta a la multitud y sabe cómo tratar con ella" (Arendt, 2008, p. 51).

8. "Es propio del hombre instruido buscar la exactitud en cada materia en la medida en que la admite la naturaleza del asunto. Evidentemente, tan absurdo sería aceptar que un matemático empleara la persuasión, como exigir de un retórico demostraciones” (Aristóteles, 1985, p. 131, 1094b 23-27).

9. "Lo que habitualmente se llama sentido común consiste en una serie de creencias admitidas en el seno de una sociedad determinada, cuyos miembros suponen que cualquier ser razonable las comparte. Pero, junto a tales creencias, existen acuerdos propios de los partidarios de una disciplina particular, ya sea de naturaleza científica o técnica, jurídica o tecnológica" (Perelman-Olbrechts Tyteca, 1989, pp. 168-9).

10. Entre enero y abril de 1919, Heidegger, flamante profesor de la Universidad de Friburgo, dicta un curso a estudiantes que, en su gran mayoría, habían combatido en la Primera Guerra Mundial. El curso lleva por título La idea de filosofia y el problema de la concepción del mundo. La especial situación histórica en la que se dicta y la peculiar característica de los asistentes, llevaron a los estudiosos del pensamiento del joven Heidegger a denominarlo como kriegsnotsemester (semestre de posguerra). 
(básicamente podemos tener una actitud participatival realizativa y una actitud contemplativa/teórica), variamos la ontología misma; por lo que no estaríamos habilitados para decir que se trata de dos actitudes ante los mismos entes. En otras palabras, si yo abandono la actitud participativa, vivencial, para adoptar la mirada distanciada, teoricista, entonces elimino del campo el elemento de significatividad que opera a nivel de la existencia cotidiana. El precio que debo pagar para poder explicar el mundo es la anulación (destrucción, desconexión) de la relación significativa originaria. Recordemos que todo acto de conocimiento objetivo se levanta sobre las ruinas del mundo natural. El movimiento que abre la esfera de la teoría es un movimiento erosionante: cancela la significación. ${ }^{11}$

El título del parágrafo 17 del curso de 1919 es toda una declaración programática: "el primado de lo teorético: la experiencia de la cosa (objetivación) como un proceso de privación de vida". Heidegger muestra lo que sucede cuando se traduce el lenguaje de la vida al lenguaje de la teoría. El imperativo de abandonar la subjetividad, la historicidad, el lenguaje materno, para elevarse al reino de la teoría (verdadero saber del mundo), arrastra tras de sí el deceso de la experiencia vital, de la enorme riqueza del ser, de la pluralidad de ordenes discursivos.

La vivencia comienza un lento y constante proceso de desaparición. "La vivencia de la determinación es solo una forma rudimentaria de la experiencia vivida, es una experiencia desvivificadora (Entleben)" (Heidegger, 2005 , p. 89). "Forma rudimentaria" significa, en esta cita, degradada, pauperizada. Lo que se degrada es la relación, el vínculo con la cosa. "En el comportamiento teorético me dirijo hacia algo, pero yo (en tanto yo histórico) no vivo en contacto con este o aquel elemento mundano" (Heidegger, 2005, p. 89).

Heidegger quiere dejar en claro la mutación ontológica que padece una cosa en función de la relación previa que la abre como tal. Subraya, además, que la ontología abierta por la actitud teorética es una ontología devaluada, empobrecida. La diferencia se advierte claramente en la siguiente situación:

Pongámonos en el lugar del astrónomo que, en el campo de la astrofísica, analiza el fenómeno de la salida del sol en términos de un proceso meramente natural, mostrándose totalmente indiferente frente a lo que pasa ante sus ojos. Contrastemos ahora esa vivencia del astrónomo con la vivencia del coro de los viejos tebanos que, en la Antígona de
Sófocles, miran al sol saliente a primera hora de la mañana después de la victoriosa defensa (de la ciudad de Tebas): "Oh, tú, el más bello rayo de sol, que desde hace tanto tiempo iluminas Las siete puertas de Tebas." (Ibid, p. 90).

¿Perciben, los ancianos y el astrónomo, el mismo objeto?

El error está en suponer que uno de los modos discursivos (en este caso el lenguaje científico) tiene un conocimiento objetivo, y por lo tanto real, mientras que el otro es poético, y por lo tanto subjetivo. La insensatez consiste en suponer que el único habilitado para responder a la pregunta “¿qué es el sol?” es el astrónomo porque tiene una metodología que le permite acceder a la "cosa en sî". El problema no es el dualismo (ni el pluralismo) de perspectivas, sino jerarquizar los modos discursivos; es decir, poner uno sobre el otro.

Es imposible traducir el lenguaje en que se expresa el modo de ser de las vivencias cotidianas al lenguaje teórico objetivo:

Estos fenómenos significativos de las vivencias del mundo circundante no los puedo explicar destruyendo su carácter esencial, suprimiendo su verdadera naturaleza y desplegando una teoría. Explicar por medio de fragmentación equivale en este contexto a destrucción: se quiere explicar algo que ya no se tiene como tal, algo que uno no puede ni quiere reconocer en su validez. [...] Cuando uno intenta explicar el mundo circundante en clave teorética este se derrumba” (Ibid, p. 104).

No hay posibilidad de transición de un universo categorial al otro; lo que hay es un salto entre diferentes marcos referenciales. Pero al saltar de un esquema a otro se varía la ontología.

En este punto, Charles Taylor es un buen heredero de la filosofía heideggeriana. Como él mismo lo confiesa, su pensamiento gira en forma obsesiva sobre un mismo problema: cómo evitar (o mejor, en qué consiste evitar) el reduccionismo naturalista.

I wanted to argue against the understanding of human life and action implicit in an influential family of theories in the sciences of man. The common feature of this family is the ambition to model the study of man on the natural sciences. Theories of this kind seem to me to be terribly implausible (Taylor, 1985, p.1).

La mayor parte de su obra puede ser leída como el intento de señalar y superar el sofisma del objetivismo,

11. Al respecto afirma uno de los más destacados estudiosos de la obra del "maestro alemán": "La significatividad puede, ciertamente, ser nivelada por la tendencia humana a cosificar u objetivar [...] la objetivación debe ser captada como "desvitalización" de la vida: por ella la vida se ve privada de su "vida", de su estructura tendencial y de los respectos de significatividad de su mundo" (Pöggeler, 1993, p. 33). 
en particular en el campo de las ciencias sociales. Taylor advierte el posicionamiento cada vez más fuerte del paradigma cartesiano de la "investigación pura", e identifica su error central en términos de una aporía: la aporía del cambio de objeto. Desandemos un poco la aporía.

$\mathrm{Al}$ igual que Heidegger, Taylor advierte que hay algo estructuralmente desencajado en la búsqueda de aplicación del conocimiento científico sobre la vida humana, sobre el ámbito de las acciones de los hombres. Puesto en el lugar del abogado de la experiencia inmediata, lo que trata de mostrar este autor es la metamorfosis que padece el objeto de experiencia cuando es traducido al lenguaje de la ciencia natural. Nuevamente, lo que late detrás del programa tayloriano es destacar la inconmensurabilidad que media entre el lenguaje ordinario y la jerga especializada.

El reduccionismo es la matriz procedimental del modelo que ataca Taylor. Por reduccionismo entendemos, en términos generales, "la afirmación de que objetos o ámbitos de cierta naturaleza pueden, al fin y a la postre, definirse o caracterizarse en términos o en componentes que corresponden a otro ámbito de naturaleza distinta" (Klimovsky, 1994, p. 275). ${ }^{12}$ Como en muchas otras circunstancias, el problema no es el modelo sino la trasgresión de las leyes que rigen su competencia. Mientras que en el campo de la química la reducción puede tener éxito (química orgánica a química inorgánica), en el campo de los asuntos humanos presenta una dificultad insuperable. Lo que sucede en este campo es que la traducción (traspaso de un campo semántico a otro) hace subrepticiamente una sustitución, o al menos una eliminación.

Un caso típico analizado por Taylor es el "proyeccionismo" en el campo de la ética. Según esta teoría, los predicados que adscriben valor a las acciones (o a los objetos) no perteneces a las acciones/objetos, sino que son un agregado nuestro. Al igual que sucede con las "cualidades secundarias" en el orden de la ontología natural, los valores no están en las cosas sino que responden al modo, siempre provinciano, de experimentar determinadas cosas por parte del agente encarnado. Así las cosas, lo que debemos hacer para obtener un conocimiento objetivo (en este caso equivalente de verdadero) es traducir los términos que asignan valor a términos que no lo hacen. Pero no solo eso; la traducción debe hacerse salva veritate. El presupuesto que guía toda la intentona del proyeccionismo, asegura que es posible separar el nivel descriptivo del significado de los términos de valor, de su fuerza valorativa. "Idealmente sería posible distinguir las mismas entidades (acciones, situaciones, cualidades) en un lenguaje puramente descriptivo, vacío de fuerza prescriptiva" (Taylor 1996, pp. 87-88).

La idea que anima esta empresa estriba en que una misma cosa puede ser descrita de diferentes maneras; es decir, puede ser abordada con diferentes lenguajes. Esta es una idea con la que podríamos acordar. Pero, como señala Taylor, la multidescripcionalidad es también ocasión para sustituir, o directamente eliminar, algunos de los referentes básicos que se quieren traducir. Si esto es así, entonces, la traducción ha sido malograda.

Un ejemplo puede resultar clarificador. En la Capilla de Arena de Padua, Giotto ha narrado en seis episodios la predicación de Cristo. En cada uno de los seis paneles, la figura predominante de Cristo se nos muestra con un brazo en alto. Sin embargo, en cada caso Jesús hace diferentes cosas: 1 . al discutir con los doctores, amonesta; 2 . en las bodas de Canaán convierte el agua en vino; 3. en el bautismo eleva el brazo como signo de pertenencia y aceptación; 4. en la tumba, ordena a su amiga muerto: "Lázaro, levántate y anda"; 5 . al ingresar a Jerusalén bendice al pueblo, y 6. en el templo expulsa de los mercaderes. Está claro que, "a pesar de esta invariable postura del brazo, con ella se nos muestra en cada escena un tipo diferente de acción y desciframos la identidad de cada acción, por el contexto en que se lleva a cabo" (Danto, 2002, p. 25). Es decir, la identidad de la acción es subsidiaria del marco referencial en la que viene a insertarse.

La tendencia objetivista, por el contrario, quiere explicar lo que sucede identificando el común denominador de las seis acciones: Jesús levanta el brazo. Para Danto esto no explica la acción, porque levantar el brazo no conforma ninguna, salvo que se inserte en un horizonte de sentido práctico que la determine como tal. Votar a favor de una ley en el Congreso de la nación no es lo mismo que llamar un taxi, aunque el movimiento que hago sea el mismo. Lo primero no puede ser reducido a lo segundo sin que desaparezca. La intentada traducción a un lenguaje neutro (descontextualizado) termina operando una desaparición del referente. No hay equivalencia extensional entre "levantó el brazo" y "votó por el candidato de la oposición".

Lo que quiero subrayar en este punto es que cada nivel discursivo se define en función de un "referente básico" que conforma su espacio lógico, su atmósfera propia. El

12. Otro modo de definir el reduccionismo lo encontramos en Thomas Nagel: "Una reducción es el análisis de algo identificado en un nivel de descripción, en términos de otro nivel de descripción considerado más fundamental, que nos permite decir que el primero en realidad no es sino el segundo" (Nagel, 2000, p. 128). 
nivel de la teoría (o de la ciencia) tiene sus propias reglas de actuación, su alcance jurisdiccional y su consecuente ontología; el campo fenomenológico vivencial el suyo. La ciencia es a la experiencia vital lo que el lenguaje formal -desambiguado y unívoco- es al lenguaje ordinario, figurado y multívoco. Ambos lenguajes son irreductibles, heterogéneos e inconmensurables. ${ }^{13}$

El hecho de que haya ciertas cosas que solo aparecen a la luz de determinados marcos referenciales, y que por lo tanto, si variamos el marco variamos los hechos, es algo que tampoco la ciencia ha podido constatar. Es ya un lugar común que ciertas propiedades de los objetos solo aparecen en determinado "nivel descripcional". Determinados hechos/características/objetos están predeterminados por el marco teórico dentro del cual adquieren realidad. Es sabido que la "solidez" es una propiedad que los objetos tienen en determinado nivel de descripción física. Cuando abandonamos ese nivel y nos paramos en la física subatómica, los objetos dejan de ser sólidos y se transforman en una "nube de moléculas". ${ }^{14}$

Un caso que siempre resulta atractivo para el filósofo y el científico es el de la "identidad personal". A mediados de los ochenta, Derek Parfit publica el intimidante e influyente libro Razones y personas. En él, ensaya un "trabajo de traducción" de esquemas conceptuales. El autor cree que el concepto de "yo" (o el reflexivo "sí-mismo") es una piedra en el zapato del pensamiento, un elemento de una mitología oscura que hay que eliminar. Para ello la estrategia es doble. Por un lado, reducir el concepto de "yo" a "la idea cartesiana del yo"; ${ }^{15}$ y por otro lado, intentar mostrar que podemos sustituir nuestro esquema conceptual personal (aquel en el que aparece el yo, la identidad personal, etc.) por un esquema conceptual impersonal, sin que se pierdan los hechos relevantes. Es decir, la traducción no solo es posible, sino muy recomendable, dado que nos liberará de pesadas cargas éticas y existenciales.
El argumento se basa en la distinción fregeana SinnBedeutung. Supongamos que un objeto tiene dos nombres. Esto es verdad respecto del planeta llamado "Venus" y "la estrella vespertina". En nuestra descripción de lo que existe, podemos decir que "Venus existe". Nuestra descripción estaría completa aunque no digamos que "la estrella vespertina existe".

Ahora bien, el siguiente paso consiste en aplicar el modelo del argumento al caso de la persona. Según Parfit, para todo enunciado en el que aparezca el concepto de (a) "yo", se puede dar la sustitución por el enunciado (b) "este conjunto de hechos psíquicos y físicos ensamblado", puesto que "la existencia de una persona no consiste en otra cosa que en la existencia de un cerebro y de un cuerpo y en la ocurrencia de una serie de sucesos físicos y mentales interrelacionados" (Parfit, 2004a, p, 389). Así las cosas, (a) y (b) tendrían la misma relación que "Venus" y "la estrella vespertina", es decir, se enmarcan dentro de la "ley de identidad" (también llamada Ley de Leibniz).

Para este autor, el esquema que elija para describir los hechos no es lo verdaderamente relevante; lo que importa son los hechos. "Lo que sostengo es que tales hechos conceptuales no pueden ser racional o moralmente importantes. Lo que importa es la realidad, no cómo es descrita" (Parfit, 2004b, p. 112). ${ }^{16}$

Adviértase el engaño del argumento: hay hechos objetivos, los esquemas conceptuales pueden variar y la mismidad del referente quedar inmunizada a tal variación. En otras palabras, lo que importa son los hechos, no el modo de describirlos.

El argumento de Parfit no parece tener en cuenta la relación de mutua implicación que existe entre esquema conceptual y hecho. Lo que constituye un "hecho" solo puede ser delimitado ad intra del marco discursivo que

13. En 1998, el reconocido filósofo Paul Ricoeur y el prestigioso neurocientífico Jean-Pierre Changeux intentan, infructuosamente, llevar adelante un diálogo sobre algunas cuestiones centrales de la ética, la estética, el conocimiento, la identidad, etc. El libro muestra con claridad la imposibilidad de encontrar un lenguaje común en el que poder entenderse. Así lo expresa, casi al comienzo, el filósofo: "Mi tesis inicial es que los discursos sostenidos en uno y otro ámbito proceden de dos perspectivas heterogéneas, es decir, no reducibles la una a la otra ni derivables una de otra. En un discurso se tata de neuronas, de conexiones neuronales, de un sistema neuronal; en el otro, se habla de conocimiento, de acción, de sentimiento, es decir, de actos o de estados caracterizados por intenciones, motivaciones, valores [...] En mi caso, parto de un dualismo semántico que expresa una dualidad de perspectivas. Lo que inclina a pasar gradualmente de un dualismo de los discursos a un dualismo de las sustancias es que cada dominio de estudio tiende a definirse respecto a lo que podemos denominar un referente ultimo; es decir, alguna cosa a la que remitirse finalmente en ese dominio. Pero ese referente solo es último en ese dominio y se define al mismo tiempo que éste" (Ricoeur-Changeaux, 1999, p. 22).

14. En la práctica científica se advierten dos tendencias opuestas. Por un lado, la apuesta reduccionista es que muchos aspectos de la realidad pueden ser reconducidos explicativamente a elementos más simples. El punto de partida, por ejemplo, afirma que el mundo está constituido íntegramente por partículas físicas y todo lo demás o es una ilusión (color, sabor), o es un rasgo superficial o superveniente (la solidez, la liquidez) que puede reducirse al comportamiento de moléculas. A esta tendencia se le puede contraponer el pluralismo descripcional, según el cual "cualquier sistema complejo se puede describir de diferentes maneras. Así, por ejemplo, el motor de un automóvil puede caracterizarse en términos de su estructura molecular, de su forma física general, de sus partes componentes, etc.” (Searle, 2006, p. 95), siendo los niveles heterogéneos e irreductibles. Toda la cuestión surge en la posibilidad o imposibilidad de pasar de un nivel a otro sin pérdida significativa.

15. Es decir, Parfit afirma que cada vez que decimos "yo", lo hacemos en términos cartesianos.

16. He efectuado un análisis algo más pormenorizado del reduccionismo de Parfit en: Blanco Ilari Juan, (2012), Hermenéutica de la ipseidad: la crítica de Paul Ricoeur al reduccionismo de Derek Parfit. Buenos Aires, Biblos. 
en cada caso se utilice. Lo que debemos evitar es suponer que hay un hecho que podemos cazar en sí, y luego, por detrás o por delante de ese hecho hay interpretaciones subjetivas (o culturales). Si esto fuera así deberíamos poder sustituir (es decir, mantener el valor de verdad) el enunciado "contrajo el párpado" por el enunciado "hizo la seña del ancho de basto". Pero esto no es posible.

Lo que trata de mostrar Taylor es que el significado de las acciones solo puede verse "desde dentro", como participante (real o posible) en el intercambio simbólico. No hay posibilidad de explicación externa.

La característica que expresamos, por ejemplo, con la palabra "solidario", no puede ser entendida fuera del contexto de uso de esa expresión. Es decir, no hay traducción posible a otro lenguaje (v.g. el de las neurociencias). Este tipo de términos solo puede ser articulado por otros términos del mismo juego o de juegos conexos. No hay comprensión desde afuera. Si esto es así, entonces entra en crisis la identificación del explanans en el caso de la mirada objetivista. En otras palabras, la identificación del objeto varía al variar el marco de referencia (internoexterno). Si no hay posibilidad de traspaso semántico, no hay traducción posible, y si no hay traducción posible, entonces el diálogo queda suspendido in limine.

\section{Conclusión}

Para finalizar, retomemos la inquietud originaria. Alain Fienkelkraut resume lo que el hombre común siente ante el avasallamiento a que se ve sometida su "experiencia", por parte del discurso externalista/objetivista, de la siguiente manera:

Ese lector se irrita al ver la experiencia humana encerrada en textos abstrusos y convertida - - colmo de desvergüenza!- en un conocimiento esotérico, en una ocupación de especialistas. [...] Lo que el profano no perdona a los filósofos es el hecho de que estos se adueńen de los problemas de todo el mundo, de que los profesionalicen, de que los oscurezcan $y$ de que por fin los restituyan, pero en un lenguaje del que queda excluido todo el mundo (Fienkelkraut, 2008, p. 17).

La situación tiene un tono inquietante. Hemos adquirido la habilidad de mirar el mundo en que vivimos en términos objetivos; es decir, desde afuera (que en realidad es "ningún lugar"), y hemos advertido que, lo que vemos desde afuera muchas veces "desmiente lo que advertimos desde dentro". ${ }^{17}$

Sin embargo, el biperspectivismo (mirada externamirada interna) se agrieta y comienza a quebrarse. Deviene en una aporía que lo obliga a rehacerse so pena de caer en el sinsentido. Repasemos, para terminar, la aporía.

Al pensamiento epistémico le es fundamental preservar la identidad del objeto analizado en relación con el objeto experienciado desde el interior de la caverna. Es decir, el pensar pretende estar articulando, aclarando, desmintiendo, explicando, algo. Ese objeto se toma del vivir cotidiano. El amor, la verdad, el bien, la percepción, etc. Se trata del momento de "fijación del explanandum"; es decir, sobre qué pensará el pensar.

Para ello necesita llevar a cabo un prolijo trabajo de traducción que permita pasar de una región a otra sin pérdida semántica relevante. El cambio de perspectiva presupone una variación en el trato que tenemos con la cosa (utilizada-pensada). Esta variación, a su vez, conlleva una crisis que tiene alcance ontológico. Lo que antes aparecía con tales o cuales características esenciales (en el sentido de definitorias de la experiencia), ahora posee otras. Así, lo que se conmociona es la mismidad del objeto sometido a dos perspectivas de análisis diferentes, heterogéneas e irreductibles. Por ello es común que, lo que comienza queriendo ser un trabajo de "traducción", termine siendo un trabajo de "sustitución velada". Si la condición de posibilidad del diálogo es el estar vinculado a un fondo lingüístico compartido, entonces estamos en presencia de un diálogo imposible (es decir, un no diálogo), pues, dos perspectivas son inconmensurables cuando no pueden encontrar un tercer leguaje que los reúna.

Lo que la aporía subraya es que al modus externalista le es estructural provocar un cambio sustancial del objeto de referencia. La muerte del objeto del trato común debe traducirse en la proposición de una nueva ontología, de un nuevo mobiliario del mundo. Un posible trabajo de traducción diría, por ejemplo, que si bien no hay brujas, lo que hay son "viejas feas con verrugas en la nariz que mezclan cosas en una marmita con la esperanza de provocar determinados efectos mágicos" que, de alguna manera, son ontológicamente equivalentes con lo que, desde otro universo lingüístico llamamos "brujas". Ahora bien, el que se ha puesto fuera de las prácticas habituales en las que ese

17. El biperspectivismo (mirada del participante-mirada objetiva) es el eje del penetrante libro de Nagel Una mirada desde ningún lugar. En él, el autor intenta una paciente búsqueda de armonización entre la mirada externa y la interna. En efecto, el problema que atraviesa todo el libro es "how to combine the perspective of a particular person inside the world with an objetive view of that same world, the person and his view point included. It is a problem that faces every creature with de impulse and capacity to transcend its particular point of view and to conceive of the world as a whole" (Nagel, 1986, p. 3). 
concepto se utiliza, deberá esforzarse por mostrar que la pretendida equivalencia, entre lo que desde el punto de vista comprometido se llaman "brujas" y lo que desde el punto de vista objetivo se presentan como "viejas feas...", es tal; es decir, debería mostrar la posibilidad de sustitución salva veritate.

En otras palabras, si quiere que advirtamos el carácter ilusorio de las cosas que pueblan el mundo de las sombras, debe identificar correctamente aquello sobre lo que ejercerá su capacidad conjuradora. Si en el submundo creemos que hay brujas y el pensar se propondrá mostrarnos lo iluso de esa creencia, entonces lo que intentará probar es que no hay brujas; o sea, no hay lo que nosotros llamamos "brujas". Debe, entonces, cerciorarse de la correcta aprehensión del explanandum.

Para ello utilizará la distinción "hecho-descripción del hecho" y tratará de demostrar que más allá de las valoraciones y descripciones que queramos hacer, hay un hecho bruto al cual podemos acceder en una mirada objetiva. Así, la postura objetivante trata de quitar de los objetos aquello que no les es inherente y quedarse con una descripción de lo que es das Ding an sich. Se asegura una descripción "neutral" que saca de la escena los elementos subjetivos.

Así, muchas de las desavenencias entre participante y observador se solucionan señalando una diferencia semántica de consecuencias ontológicas.

Barry Stroud nos convida un ejemplo en el que se resume, con la plasticidad de una imagen, qué significa para nosotros la diferencia discursiva y cómo, en última instancia, debe impactar en nuestras prácticas cotidianas. Cito in extenso y cierro:

Supóngase que alguien da una noticia sumamente sorprendente acerca de que no existe ni un solo médico en la cuidad de Nueva York. Ciertamente parece que esto va en contra de algo que todos considerábamos verdadero. Sería realmente asombroso si no hubiese ningún médico en una ciudad de este tamaño. En el momento en que preguntásemos cómo se hizo este extraordinario descubrimiento y por cuánto tiempo ha prevalecido esta situación, supóngase que descubrimos que el portador de esta sorprendente noticia dice que es verdadera porque, según él explica, lo que él entiende por "médico" es una persona que tiene un grado en medicina y puede curar cualquier enfermedad concebible en menos de dos minutos. No estaremos ya sorprendidos por su anuncio, ni pensaremos que contradice algo que todos considerábamos saber que era verdadero. Nos parece bastante creíble que no haya ninguno en toda la ciudad que cumpla todas las condiciones de esta peculiar "redefinición" de "médico". Una vez que lo entendemos como se suponía había que en- tenderlo, no hay nada asombroso en la noticia excepto quizá la forma en que fue expresada. No niega lo que a primera vista pudiera aparentemente negar y no significa ninguna amenaza para nuestra creencia original de que existen miles y miles de médicos en Nueva York (Stroud, 1991, pp. 42-43).

\section{Referencias}

Agamben, G. (2007). Infancia e historia. Buenos Aires: Adriana Hidalgo Editora.

Arendt, H. (2008). La promesa de la politica. Barcelona: Paidós. Arendt, H. (2002). La vida del espíritu. Buenos Aires. Paidós. Aristóteles, (1985). Ética a Nicómaco. Madrid: Gredos.

Blanco-Ilari, J. (2012). Hermenéutica de la Ipseidad: la crítica de Paul Ricoeur al reduccionismo de Derek Parfit. Buenos Aires: Biblos.

Danto, A. (2002). La transfiguración del lugar común. Barcelona. Paidós.

Fienkelkraut, A. (2008). La sabiduría del amor. Barcelona: Gedisa.

Gadamer, H. G. (1998). El giro hermenéutico. Madrid: Cátedra.

Hediegger, M. (2005). La idea de filosofía y el problema de la concepción del mundo. Barcelona: Herder.

Jay, M. (2009). Cantos de experiencia. Buenos Aires: Paidós.

Klimovsky, G. (1994). Las desventuras del conocimiento cientifico. San Pablo: A-Z editora.

Nagel, T. (1986). The View from Nowhere. Oxford: Oxford University Press.

Nagel, T. (2000). Otras mentes. Barcelona: Gedisa.

Parfit, D. (2004a). Razones y personas. Madrid: Machado.

Parfit, D. (2004b). Personas, racionalidad y tiempo. Madrid: Síntesis.

Perelman, Ch., \& Olbrechts T. L. (1989). Tratado de la argumentación. Madrid: Gredos.

Pöggeler, O. (1993). El camino del pensar de Martin Heidegger. Madrid: Alianza.

Presas, M. (2009). Del ser a la palabra. Buenos Aires: Biblos.

Ricoeur, P., \& Changeaux J. P. (1999). Lo que nos hace pensar, la naturaleza y la regla. Barcelona: Península.

Searle, J. (2006). La mente, una breve introducción: Bogotá: Norma.

Stroud, B. (1991). El escepticismo filosófico y su significación. México: Fondo de Cultura Económica.

Taylor, C. (1985). Human agency and language. Cambridge: Cambridge University Press.

Taylor, C. (1996). Fuentes del yo. Barcelona: Paidós.

Taylor, C. (1997). Argumentos filosóficos. Barcelona: Paidós. 